Dragoslava N. Mićović ${ }^{* *}$

Kriminalističko-policijski

univerzitet u Beogradu https://doi.org/10.18485/analiff.2020.32.1.12

$371.3:: 811.111 ’ 373.6$

Originalni naučni rad

Primljen: 02.03.2020.

Prihvaćen: 13.06.2020.

\title{
UTICAJ FONDA USVOJENIH REČI NA RAZUMEVANJE PROČITANOG STRUČNOG TEKSTA NA ENGLESKOM JEZIKU - PILOT ISTRAŽIVANJE
}

U radu su predstavljeni rezultati pilot istraživanja koje je obavljeno u toku dve akademske godine sa studentima prve godine forenzičkog inženjerstva naKriminalističko-policijskom univerzitetu u Beogradu. Cilj istraživanja bio je da se utvrdi da li postoji, i ako postoji kakva je veza između fonda reči usvojenog tokom prethodnog školovanja sa razumevanjem pročitanog stručnog teksta. U tom smislu, u radu je najpre dat kratak pregled prethodnih sličnih istraživanja, koja su sprovedena širom sveta u različitim sredinama gde se uči engleski jezik. Sva istraživanja potvrdila su da postoji veza između poznavanja reči i razumevanja pročitanog teksta. Naše pilot istraživanje razlikuje se od prethodno navedenih po tome što smo pokušali da utvrdimo vezu između poznavanja reči i razumevanja stručnog teksta, dakle u kontekstu engleskog jezika struke. Podaci koje smo prikupili upitnikom i rezultati koji su dobijeni testiranjem ispitanika obrađeni su statistički. Nakon predstavljanja rezultata i diskusije o njima, u zaključku su između ostalog ponuđeni i predlozi za buduća istraživanja veze između fonda reči i razumevanja pročitanog stručnog teksta.

Ključne reči: fond reči, razumevanje pročitanog teksta, pilot istraživanje, engleski jezik struke, test obima vokabulara, stručni tekst

\section{Uvod}

Kako reči čine sastavni deo jezika, sasvim je jasno da bez poznavanja reči ne bismo mogli ni da se izrazimo, niti da razumemo pisanu ili izrečenu poruku. Poznavanje određenog fonda reči, kako na maternjem tako i na stranom jeziku, omogućava nam precizno izražavanje i razumevanje pročitanog teksta. Sa druge strane, ekstenzivno čitanje u velikoj meri utiče

\footnotetext{
* Kriminalističko-policijski univerzitet, Cara Dušana 196, Zemun, Beograd, dragoslava.micovic@kpu.edu.rs
} 
na fond reči koje usvajamo tako što ga unapređuje, jer čitanjem učimo nove reči, ali i nova značenja reči koje već poznajemo. Dakle, slobodno možemo da kažemo da pored ostalih elemenata čitanje igra ključnu ulogu u usvajanju nekog jezika, naročito u učenju drugog ili stranog jezika. Zbog toga je važno da nastavnici obezbede svojim studentima da usvoje adekvatan vokabular kako bi bili u stanju da čitaju i dobro razumeju akademske, ali i stručne tekstove. Međutim, veza između sposobnosti da se razume pročitan tekst i obima vokabulara je i kompleksna i dinamična $(\mathrm{Hu}$ \& Nation, 2000). Stoga se može reći da je poznavanje vokabulara vitalna komponenta učenja jezika koja se mora uzeti u obzir prilikom unapređivanja veštine razumevanja pročitanog teksta, pored poznavanja engleske gramatike i ostalog opšteg znanja (eng. background knowledge) (Ibrahim et al, 2016).

Od ključne je važnosti znati šta je potrebno da neko ko uči jezik razume šta čita, pogotovo kada se susretne sa čitanjem tekstova stručne odn. profesionalne prirode, drugim rečima sa engleskim jezikom struke, u kome poznavanje adekvatne terminologije igra dodatnu ulogu uz poznavanje vokabulara opšteg jezika. Iz tog razloga u ovom istraživanju pokušali smo da istražimo odnos između fonda usvojenih reči i razumevanja pročitanog stručnog teksta na engleskom jeziku.

\section{Prethodna slična istraživanja}

U oblasti istraživanja vokabulara, odnosno preciznije usvajanja reči i veze između poznavanja određenog fonda reči i njihovog uticaja na čitanje i razumevanje teksta na engleskom jeziku, sprovedeno je dosta raznovrsnih istraživanja širom sveta, a njihovi rezultati objavljivani su većim delom kao članci u stručnim časopisima, ali i kao magistarske teze i doktorske disertacije. Uglavnom su se ova istraživanja bavila odnosom fonda reči i razumevanja pročitanog teksta i za sve je zajedničko da polaze od pretpostavke da je ova veza neosporna, pri čemu je jedan broj ovih istraživanja i jasno pokazao da ta veza postoji.Tako, na primer, Moghadam et el. (2012) navode dajedan broj istraživanja u kontekstu učenja engleskog jezika kao stranog pruža dokaze o odnosu između poznavanja vokabulara i uspešnog razumevanja pročitanog teksta.Zhang and Anual (2008) istraživali su ulogu vokabulara u razumevanju pročitanog teksta sa 39 srednjoškolaca koji uče engleski u Singapuru i tom prilikom koristili su testovepoznavanja 
nivoa vokabulara ${ }^{1}$ (Vocabulary Level Tests). Njihovi rezultati su pokazali da je fond reči od 2000 i 3000 reči bio u korelaciji sa razumevanjem pročitanog teksta $i$ to tako da postoji bliska veza između poznavanja vokabulara i razumevanja pročitanog teksta na engleskom jeziku. Pored ovog istraživanja, Martin-Chang i Gould (2008) utvrdili su jaku korelaciju između vokabulara i razumevanja pročitanog teksta, u smislu da je poznavanje vokabulara fundamentalno u razumevanju pročitanog teksta, jer funkcioniše na identičan način kao i opšte poznavanje neke oblasti (tzv. background knowledge) prilikom razumevanja pročitanog teksta. Poznavanje vokabulara olakšava dekodiranje koje čini značajan deo čitanja (Qian, 2002).

Postoji još istraživanja koja pokazuju vezu između poznavanja vokabulara i razumevanja pročitanog teksta, kao na primerAlderson (2000), Joshi (2005), Joshi and Aron(2000), Manyak and Bauer (2009)iRickets et al. (2007). Mali fond reči, ali i nedostatak adekvatnog značenja neke reči, obično predstavljaju prepreku da se razume značenje teksta. Jedan broj istraživanja - Baleghizadeh i Golbin (2010), Huang (2006), Koda(1989),Laufer (1992),Laufer(1996), Mehrpour et al. (2011), Shen (2008) and Zhang (2008) - uzima rezultat na testu obima vokabulara kao osnovu za predviđanje nivoa razumevanja akademskog pročitanog teksta. Laufer (1996) je u svojim istraživanjima otkrila značajne korelacije između različitih tipova testova za utvrđivanje obima vokabulara i testova za proveru razumevanja pročitanog teksta. U svom istraživanju sa 92 studenta prve godine univerziteta čiji je maternji jezik hebrejski ili arapski (Laufer, 1992), ona je koristila dve vrste testova za utvrđivanje fonda reči i dobila dve različite korelacije: korelacija između rezultata na testu nivoa vokabulara i rezultata testa za proveru razumevanja pročitanog teksta bio je 0.50 , što je umerena korelacija, dok je korelacija između rezultata testa vokabulara Eurocentra (Meara, 1990) i rezultata na proveri razumevanja pročitanog teksta bila 0.75.U istraživanju koje je sproveo Pringprom 2011. godine (Pringprom, 2011, navedeno prema: Moghadam et al., 2012) sa 30 studenata osnovnih studija na Univerzitetu u Bangkoku takođe je utvrđeno

1 Radi boljeg razumevanja terminologije koja se koristi, u radu se najčešće koristi termin „fond reči“. Međutim, nekada je bilo neophodno da se upotrebi i druga terminologija u skladu sa nazivima testova koje su koristili različiti istraživači. Zato se negde u tekstu pominje „nivo vokabulara“, a negde „obim vokabulara“, što je zapravo prevod naziva testova, pri čemu se i ovi termini zapravo odnose na fond reči. 
da postoji pozitivna korelacija između poznavanja fonda reči na engleskom i razumevanja pročitanog teksta.

Neka novija istraživanja koja su vršena u kontekstu učenja stranog jezika utvrdila su visoku i pozitivnu korelaciju između poznavanja vokabulara i razumevanja pročitanog teksta, mada su ona ispitivala i dubinu i širinu poznavanja vokabulara (Moghadam et el., 2012).

Ovde pomenuta istraživanja uglavnom su vršena u kontekstu poznavanja opšteg engleskog jezika, i eventualno engleskog jezika za akademske namene, dok se nigde ne spominje istraživanje u kontekstu engleskog jezika neke određene struke, što je kontekst u kojem je sprovedeno naše pilot istraživanje.

\section{Istraživanje}

Naše istraživanje zamišljeno je kao pilot istraživanje. Po definiciji ovakvo istraživanje predstavljaprobnu anketu u kojoj je broj ispitanika veoma mali, ali je od velike koristi jer se greške mogu otkloniti pre početka šireg ispitivanja (Giddens, 2009).Iako pilot istraživanje ne garantuje uspeh glavnog istraživanja, ono u velikoj meri povećava izvesnost uspeha ( $\mathrm{Si}$ mon, 2012).

\section{Cilj istraživanja}

Cilj našeg istraživanja bio je da se utvrdi da li postoji i ako postoji kakva je veza, pre svega između broja godina učenja engleskog jezika i usvajanja određenog fonda reči, a zatim i između tog fonda usvojenih reči i razumevanja pročitanog stručnog teksta kod ispitanika iz našeg uzorka, odnosno studenata Kriminalističko-policijskog univerziteta.

\section{Upitnik i testovi korišćeni u istraživanju}

Prikupljanje podataka za ovo istraživanje odvijalo se u tri etape i sadrži tri elementa. Prva etapa jeste prikupljanje osnovnih podataka o ispitanicima relevantnih za ovo istraživanje putem upitnika. Upitnik se sastojao od pitanja otvorenog tipa i obuhvatio je pitanja koju vrstu škole su ispitanici prethodno pohađali (da li je pitanju bila srednja stručna škola ili gimnazija), te koliko godina su učili engleski jezik tokom prethodnog školovanja.

Druga etapačinila je testiranjeobima vokabulara putem testa čiji je autor Pol Nejšen (Paul Nation). Test obima vokabulara ili test fonda 
reči(Vocabulary Size Test) sačinjen je da meri obim receptivnog vokabulara engleskog jezika kod onih koji ga uče i kao prvi i kao drugi jezik. Test meri znanje pisanog oblika reči, vezu između oblika i značenja i u manjoj meri poznavanje pojma. U testu su primeri dati u rečenici, ali u rečenici izvan konteksta. Dakle, test u suštini meri poznavanje pisanog receptivnog vokabulara, tj. poznavanje vokabulara neophodnog za čitanje. On ne meri poznavanje vokabulara potrebnog za slušanje, govor ili pisanje, i u tom smislu rezultati testa malo toga će moći da kažu o tome koliko dobro bi ispitanik upotrebio iste reči u govoru ili pisanju. Isto tako, on nije mera veštine čitanja, jer iako obim vokabulara jeste kritični faktor kod čitanja, on je samo jedan deo veštine čitanja.

Test obima vokabulara ima nekoliko verzija, a u našem istraživanju korišćena je verzija od 14.000 reči sa više ponuđenih odgovora (Nation, 2007), koju sam Nejšen navodi kao najbolju verziju za neizvorne govornike engleskog jezika.

Izbor jedinica u testu vršen je tako da predstavljaju određeni nivo učestalosti reči u jeziku, a koji se zasniva na porodicama reči ${ }^{2}$ koje se javljaju u Britanskom nacionalnom korpusu (British National Corpus)do nivoa 6 prema Baueru i Najšenu ${ }^{3}$ (Bauer \& Nation, 1993).

Uobičajeno vreme potrebno za izradu testa je 40 minuta za 140 pitanja.Ukupan rezultat tačnih odgovora na kraju se množi sa 100 kako bi se dobio broj reči koje ispitanik zna. To znači, na primer, da će rezultat od 35 od 140 pitanja značiti da je obim vokabulara ispitanika 3500 porodica reči.

2 Porodice reči ili klasteri reči jesu leksičke grupe sa semantički i fonemski identičnim korenskim morfemama, kao na primer life, lifeless, lifelike, lifeline, lifelong, lifer, life-size, lifetime, lifebelt, lifeblood, lifeboat, lifebuoy, life-cycle, lifeguard, lifejacket; ... (Milojević, 2000: 207).

3 Ovde je reč o nivoima usvajanja jedne porodice reči prema ovim autorima. Naime, Bauer i Nejšen kažu da se sa stanovišta onoga ko čita neki tekst porodica reči sastoji od jedne osnovne reči i svih oblika koji su iz nje izvedeni, a koje on može da razume bez da je neophodno da uči svaki oblik ponaosob. Veličina jedne porodice reči raste kako raste i znanje o sufiksima i prefiksima kod onoga ko uči engleski jezik. U tom smislu su ova dva autora formirala šest nivoa usvajanja sufiksa i prefiksa, pri čemu se na nivou 1 svaki oblik računa kao različita reč, dok na primer četiri reči sa nivoa 1 postaju jedna porodica reči na nivou 2. Ovim nivoima se utvrđuje i redosled učenja određenih sufiksa i prefiksa. Više o kriterijumima određivanja nivoa u: Bauer \& Nation, 1993. 
Upitnik i test studenti popunjavaju na početku semestra kada slušaju predmet Engleski jezik 1. Iako se ovim testom može okvirno utvrditi broj porodica reči koje ispitanici poznaju, moramo da napomenemo da on ipak ne sadrži stručne termine karakteristične za policijsku i forenzičku terminologiju koja se uči u okviru predmeta Engleski jezik 1 na osnovnim akademskim studijama forenzičkog inženjerstva na Kriminalističko-policijskom univerzitetu u Beogradu.

Treća etapaistraživanja odnosi se na testiranje razumevanja pročitanog stručnog teksta. Ovaj deo obuhvata kolokvijum koji čini deo predispitnih obaveza u toku prvog semestra prve godine studija Forenzičkog inženjerstva na predmetu Engleski jezik 1.Test ukupno nosi 30 poena. Testom se meri razumevanje pročitanog stručnog teksta na engleskom jeziku i sastoji se od dva dela: prvi deo testa odnosi se na duži tekst na engleskom jeziku koji su studenti obavezni da pročitaju pre kolokvijuma i da na kolokvijumu odgovaraju na pitanja u vezi sa njim, pri čemu test sadrži 20 pitanja koja su kombinacija klasičnih pitanja i započetih tvrdnji koje treba dovršiti. Na svako pitanje ponuđeno je tri odgovora od koji je samo jedan tačan. Ovaj deo nosi 20 od ukupno 30 poena. Drugi deo testa odnosi se na kratak stručni tekst koji studenti prvi put vide i u kome su izostavljene određene reči. Za svako prazno mesto nudi se četiri odgovora od kojih je takođe samo jedan tačan. Pitanja je 10 i ovaj deo testa nosi 10 od ukupno 30 poena. Kako je reč o studentima osnovnih akademskih studija forenzičkog inženjerstva, tekstovi koji se koriste na testu jesu iz policijske i forenzičke oblasti.Kada je reč o težini tekstova koji su korišćeni za testiranje razumevanja pročitanog teksta, oni bi mogli da se svrstaju u kategoriju tekstova sa rečima srednje frekvencije prema kategorizaciji koju je utvrdio Nejšen $^{4}$ (Nation, 2006).

Prikupljeni podaci statistički su obrađeni korišćenjem programa za obradu podataka po imenu R, verzija 3.6.1. R (R-Project) je jezik i okruže-

$4 \quad$ Istražujući koliki fond reči je potreban za čitanje određene vrste teksta i koliki procenat nepoznatih reči u okviru teksta onemogućava razumevanje teksta, Nejšen je došao do rezultata da je za čitanje lektire adaptirane po nivoima (graded readers) koja sadrži reči visoke frekvencije potrebno poznavati od 1000 do 2000 porodica reči, za lektiru adaptiranu po nivoima koja sadrži reči srednje frekvencije neophodno je poznavanje između 3000 i 9000 porodica reči, a za čitanje širokog spektra tekstova koji sadrže reči niske frekvencije neophodno je poznavanje više od 10000 porodica reči. 
UTICAJ FONDA USVOJENIH REČI NA RAZUMEVANJE PROČITANOG ...

nje za statističko računanje i grafiku koji može da se poredi sa popularnim komercijalnim statističkim paketima kao što su SAS, SPSS i Stat, ali R je korisnicima dostupan besplatno (Burns, 2006).

\section{Uzorak}

Kao što smo napred izneli, cilj istraživanja bio je da se utvrdi da li postoji i ako postoji kakva je veza između broja godina učenja i fonda usvojenih reči, odnosno fonda prethodno usvojenih reči i razumevanja stručnog pročitanog teksta na engleskom jeziku. U te svrhe sprovedeno je istraživanje je na Kriminalističko-policijskom univerzitetu u Beogradu i u njemu su učestvovali studenti prve godine osnovnih akademskih studija Forenzičkog inženjerstva koji su se dobrovoljno prijavili za istraživanje. Istraživanje je trajalo u toku zimskog semestra dve školske godine, 2018/2019 i 2019/2020. Studenti su u oba slučaja pohađali predmet Engleski jezik 1. Uzorak je obuhvatio ukupno 29 studenata, 19 u toku 2018/2019 šk. godine i 10 u toku šk. 2019/2020 godine, od toga 2 studenta i 27 studentkinja.

Osnovni podaci o ispitanicima prikupljeni upitnikom dati su u Tabeli 1:

\begin{tabular}{|c|c|c|c|}
\hline $\begin{array}{c}\text { Redni } \\
\text { broj }\end{array}$ & $\begin{array}{c}\text { Godine } \\
\text { učenja }\end{array}$ & $\begin{array}{c}\text { Prethodno } \\
\text { usvojeni fond reči } \\
\text { (test P. Nation) }\end{array}$ & $\begin{array}{c}\text { Broj poena na testu } \\
\text { razumevanja pročitanog } \\
\text { teksta (max. 30) }\end{array}$ \\
\hline 1 & 12 & 2000 & 17 \\
\hline 2 & 8 & 2400 & 23 \\
\hline 3 & 4 & 2900 & 16 \\
\hline 4 & 8 & 3000 & 19 \\
\hline 5 & 12 & 3200 & 29 \\
\hline 6 & 12 & 3300 & 30 \\
\hline 7 & 12 & 4200 & 27 \\
\hline 8 & 12 & 4500 & 22 \\
\hline 9 & 12 & 4700 & 21 \\
\hline 10 & 9 & 5100 & 22 \\
\hline 11 & 10 & 5200 & 24 \\
\hline 12 & 9 & 5500 & 25 \\
\hline
\end{tabular}


Dragoslava N. Mićović

\begin{tabular}{|l|l|l|l|}
\hline 13 & 12 & 5500 & 29 \\
\hline 14 & 12 & 6100 & 25 \\
\hline 15 & 12 & 6100 & 23 \\
\hline 16 & 12 & 6100 & 27 \\
\hline 17 & 12 & 6100 & 27 \\
\hline 18 & 12 & 6400 & 19 \\
\hline 19 & 12 & 6500 & 24 \\
\hline 20 & 12 & 6600 & 21 \\
\hline 21 & 12 & 6700 & 24 \\
\hline 22 & 12 & 7200 & 27 \\
\hline 23 & 12 & 7300 & 16 \\
\hline 24 & 12 & 7400 & 29 \\
\hline 25 & 12 & 7900 & 26 \\
\hline 26 & 13 & 8600 & 25 \\
\hline 27 & 13 & 8700 & 27 \\
\hline 28 & 12 & 9200 & 20 \\
\hline 29 & 12 & 10100 & 30 \\
\hline
\end{tabular}

Kao što se iz Tabele 1 može videti, u prethodnom školovanju svi su učili engleski jezik, ali je period učenja varirao od četiri do trinaest godina. Petnaest studentkinja i jedan student prethodno su pohađali neku od srednjih stručnih škola (uglavnom su to medicinska, hemijska, zubotehnička i škole sličnih prirodnih usmerenja), a dvanaest studentkinja i jedan student pohađali su gimnaziju (pretežno prirodnog smera). Rezultati na ulaznom testu obima vokabulara pokazali su da se broj porodica reči koje su naši ispitanici usvojili tokom prethodnih godinaučenja engleskog jezika kretao od 2000 do 10100, a broj poena na testu razumevanja pročitanog stručnogteksta kretao se od 16 (što i jeste bio minimum da bi se smatralo da je student položio kolokvijum) do maksimalnih 30 poena.

Podacima koje smo prikupili treba da se utvrdi sledeće: prva korelacijatrebalo bi da pokaže da li broj godina učenja ima veze sa brojem usvojenih reči, a druga korelacija da li broj usvojenih reči utiče na uspeh na testu provere razumevanja pročitanog stručnog teksta.

Prethodno smo već naveli da postoje brojna istraživanja kojima je utvrđeno i potvrđenoda fond reči utiče na sposobnost čitanja i razumeva- 
nja pročitanog teksta. Našim uzorkom trebalo bi da se utvrdi da li ovakva veza postoji i kada je reč o jeziku struke, odn. kada su predmet čitanja stručni tekstovi na engleskom jeziku. Pored toga, ovo istraživanje trebalo bi da pokaže da li su prikupljeni podaci dovoljni da se izvede zaključak i da li ih eventualno treba korigovati prilikom narednih istraživanja.

\section{Rezultati i diskusija}

Rezultati koje smo dobili u našem istraživanju i njihova korelacija obrađena programom $\mathrm{R}$ grafički su prikazani na Slici 1:

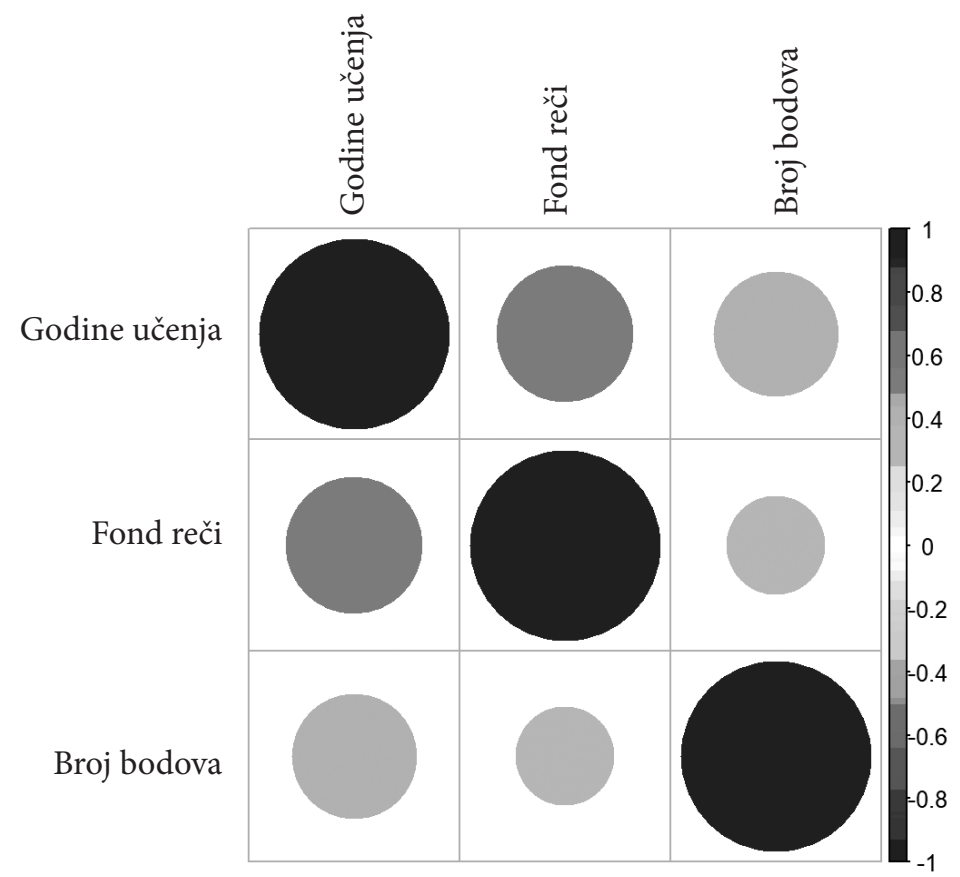

\#\#

Fond reči Godine učenja

\#\# Fond reči

1.0000000

0.5180025

\#\# Godine učenja 0.5180025

1.0000000

\#\#

Fond reči $\mathrm{Br}$. bodova

$\begin{array}{llll}\text { \#\# Fond reči } 1.0000000 & 0.2679381\end{array}$

\#\# $\mathrm{Br}$. bodova 0.26793811 .0000000 
Korelacija između promenljivih prikazana je u parovima. Sa strane se nalazi skala jačine korelacije, a koeficijent se pravljen tako da uzima vrednosti između -1 i 1 . Ako je koeficijent blizak jedinici, to znači da je prisutna jaka pozitivna korelacija, što znači da porastom jedne promenljive raste i druga (,povlače“ jedna drugu). Ako je bliži -1, imamo negativno korelaciju, što praktično znači da porastom jedne druga opada.

$\mathrm{Na}$ osnovu ovog uzorka, koeficijent korelacije između broja godina učenja i fonda reči je oko 0.5 , dakle imamo umerenu pozitivnu korelaciju, dok je koeficijent između fonda reči i broja bodova nesto manji i iznosi 0.3, što predstavlja slabu pozitivnu korelaciju. Ovo ukazuje da postoji pozitivna veza u oba slučaja, ali je ona jača u prvom slučaju. Drugim rečima, veća korelacija postoji između broja godina učenja engleskog jezika i fonda usvojenih reči. Da bismo rekli da postoji jaka veza izmedju promenljivih, koeficijent bi trebalo da bude veći od 0.8. Vrednosti koje smo mi dobili govore u prilog tome da određena veza postoji u oba slučaja, ali da ona nije preterano jaka. Da ne postoji nikakva veza, koeficijent bi bio jako blizak nuli, što ovde ipak nije slučaj.

Kada uporedimo sa istraživanjima o kojima je bilo reči na početku rada, vidimo da je i naše istraživanje potvrdilo postojanje veze između fonda reči/poznavanja vokabulara i razumevanja pročitanog teksta. Posebno je važno istaći da su u našem istraživanju korišćeni stručni tekstovi, a testom obima vokabulara utvrđeno je poznavanje opšteg vokabulara. Stoga možemo da zaključimo da korelacija između ove dve promenljive postoji, ali reč je o slaboj pozitivnoj korelaciji.Ovakvi rezultati govore i u prilog tome da bi ovo pilot istraživanje moglo da bude modifikovano na neki način kako bi se dobili precizniji podaci, kao i da postoji mogućnost da bi povećanjem uzorka moglo da se utiče na rezultate.

\section{Zaključak}

Cilj pilot istraživanja koje je sprovedeno na Kriminalističko-policijskom univerzitetu bio je da se utvrdi veza između broja godina učenja engleskog jezika $i$ fonda reči koji se tokom tog perioda usvaja, kao i da utvrdi da li postoji i kakva je veza između tog usvojenog fonda reči i sposobnosti studenata da sa tim fondom reči razumeju pročitani stručni tekst ne engleskom jeziku. Dobijeni rezultati potvrdili su da postoji korelacija i između broja godina učenja i fonda usvojenih reči i veza između usvoje- 
nog fonda reči i razumevanja pročitanog teksta. Međutim, u našem slučaju prva korelacija je jača nego druga.

U prethodnim sličnimistraživanjima ispitivana je veza između fonda reči i razumevanja pročitanog teksta, međutim testovi kojima se utvrđuje nivo ili obim vokabulara, i tekstovi korišćeni za razumevanje pročitanog teksta odnosili su se uglavnom na opšti engleski jezik, pa su i utvrđene korelacije bile jače. U našem slučaju, postoji razlika jer su korišćeni testovi za utvrđivanje obima vokabulara koji pokrivaju opšti jezik, a testirano je razumevanje pročitanog stručnog teksta, pa je dobijena korelacija pozitivna, ali slabija nego što je to slučaj kada je reč o tekstovima iz opšteg jezika.Da bi se bliže ispitala ova korelacija u budućnosti, trebali bi i da se test za utvrđivanje obima vokabulara prilagodi na taj način što bi testirao i poznavanje stručne terminologije.

$\mathrm{Na}$ osnovu ovog pilot istraživanja takođe smatramo daprilikom prikupljanja podataka za buduća istraživanja od ispitanika treba prikupiti i dodatnepodatke o uspehu tokom prethodnog (srednjoškolskog) obrazovanja i podatke o uspešnosti na prijemnom ispitu, za koje smatramo da bi bili pokazatelji opšteg znanja ispitanika (background knowledge). Naime, opšte znanje je jedan od faktora koji se takođe smatra relevantnim i važnim za dekodiranje, odn. razumevanje teksta.

Što se tiče veze između usvojenog vokabulara i razumevanja pročitanog stručnog teksta, testiranje razumevanja bi trebalo ponoviti još jednom na kraju semestra kada ispitanici odslušaju predmet Engleski jezik 2, pošto tokom slušanja predmeta Engleski jezik 1 i Engleski jezik 2 uče i stručnu terminologiju. Testiranje nakon završetka dva semestra učenja stranog jezika struke pokazalo bi u kojoj meri su usvojili i stručnu terminologiju, a rezultati bi tada trebalo da pokažu da li ova novousvojena stručna terminologija ima veći uticaj na razumevanje pročitanog stručnog teksta na engleskom jeziku. 


\section{LITERATURA}

Alderson, J. C. (2000). Assessing Reading. Cambridge, United Kingdom: Cambridge University Press.

Baleghizadeh, S., \&Golbin, M. (2010).The Effect of Vocabulary Size on Reading Comprehension of Iranian EFL Learners.LiBRI. Linguistic and Literary Broad Research and Innovation ,1(2), 33-46.

Bauer, L., \& Nation, I. S. P. (1993). Word families. International Journal of Lexicography, 6(4), 253-279.

Burns, P. (2006). R Relative to Statistical Packages: Comment 1 on Technical Report Number 1 (Version 1.0) Strategically using General Purpose Statistics Packages: A Look at Stata, SAS and SPSS (1). Retrieved from http://www. burns-stat.com/pages/Tutor/R_relative_statpack.pdf, pristup 25. 01. 2020.

Giddens, A. (2009). Sociology (6th ed.). Cambridge, UK: Polity Press.

$\mathrm{Hu}, \mathrm{M} .$, \& Nation, I. S. P. (2000).Unknown vocabulary density and reading comprehension.Reading in a Foreign Language, 13(1), 403-430.

Huang HF. Breadth and Depth of Vocabulary Knowledge: Which Really Matters in the Academic Reading performance of Chinese University Students? A thesis submitted to Department of Integrated Studies in Education McGill University, Montreal, January 2006, dostupno na: http://digitool.library. mcgill.ca/webclient/StreamGate?folder_id=0\&dvs=1580557942181 989, pristup: 24. 01. 2020.

Ibrahim, E. H. E., Sarudin, I., \&Muhamad, A. J. (2016).The Relationship between Vocabulary Size and Reading Comprehension of ESL Learners.English Language Teaching, 9(2), 116-123.

Joshi, M. R. (2005). Vocabulary: A Critical Component of Comprehension. Reading and Writing Quarterly, (21), 209-219.

Joshi, M. R., \&Aron, P. G. (2000). The component model of reading: Simple view of reading made a little more complex. Reading Psychology , (21), 85-97.

Koda, K. (1989). The effects of transferred vocabulary knowledge on the development of L2 reading proficiency.Foreign Language Annals , (22), $529-540$.

Laufer, B. (1992). How much lexis is necessary for reading comprehension? . In P. J. L. Arnaud \& H. Béjoint (Eds.), Vocabulary and Applied Linguistics (pp. 126-132). London: Palgrave Macmillan.

Laufer, B. (1996). The lexical threshold of second language reading comprehension: What it is and how it relates to L1 reading ability. In K. Sajavaara\& C. Fairweather(Eds.), Approaches to second language acquisition (pp. 5562). Jyvaskyla, Finland: University of Jyvaskyla. 
Manyak, P. C., \& Bauer, E. B. (2009). English vocabulary instruction for English learners. The Reading Teacher, 63(2), 174-176.

Martin-Chang, S. L., \& Gould, O. N. (2008). Revisiting print exposure: Exploring differential links to vocabulary, comprehension and reading rate.Journal of Research in Reading, 31(3), 273-284.

Meara, P. and Jones G. (1990).Eurocentres Vocabulary Size Tests 10KA. Zurich: Eurocentres Learning Service.

Mehrpour, S., Razmjoo, S. A., \&Kian, P. (2011).The Relationship between Depth and Breadth of Vocabulary Knowledge and Reading Comprehension among Iranian EFL Learners.Journal of English Language Teaching and Learning , (222), 97-127.

Milojević, J. (2000). Word and Words of English: English Morphology A-Z. Belgrade: Papirus.

Moghadam, S. H., Zainal, Z., \&Ghaderpour, M. (2012). A Review on the Important Role of Vocabulary Knowledge in Reading Comprehension Performance.Procedia - Social and Behavioral Sciences, 66, 555-563. Dostupnona:https://core.ac.uk/download/pdf/82106237.pdf

Nation, I. S. P., (2006). How large a vocabulary is needed for reading and listening? Canadian Modern Language Review, 63(1), 59-82.

Nation, I.S.P. \& Beglar, D. (2007) A vocabulary size test. The Language Teacher, 31(7), 9-13.

Qian, D. (2002). Investigating the relationship between vocabulary knowledge and academic reading performance: An assessment perspective.Language Learning , (52), 513-536.

Ricketts J, Nation K, Bishop D. (2007).Vocabulary is important for some, but not all reading skills. Scientific Studies of Reading, 11(3), 235-257.

Shen, M. Y. (2008). EFL learners' responses to extensive reading: survey and pedagogical applications. The Reading Matrix, 8(2), 111-123.

Simon, M. K., \& Goes PhD, J. (2012).Dissertation and Scholarly Research: Recipes for Success: 2013 Edition (2013 edition). Zaltbommel, Netherlands: Van Haren Publishing.

The R Project for Statistical Computing.(n.d.).Pristup:25. 01. 2020, na:https:// www.r-project.org/about.html

Zhang, L. J., \&Anual, S. B. (2008). The role of vocabulary in reading comprehension: the case of secondary school students learning English in Singapore. RELC Journal, 39(1), 51-76. 


\title{
Dragoslava N. Mićović
}

\section{INFLUENCE OF VOCABULARY SIZE ON READING COMPREHENSION OF ESP TEXTS - PILOT STUDY}

\begin{abstract}
Summary
A number of studies have demostrated that there is a link between vocabulary knowledge and reading comprehension. This paper presents the results of a pilot study carried out during two academic years with the freshmen of University of Criminal Investigation and Police Studies in Belgrade. The goal of the study was to establish if there is, and if there is, which is the relationship between the vocabulary size adopted during previous education and technical text reading comprehension. The paper first gives an overview of previous similar research, which has been conducted worldwide in various English learning environments. All researches have confirmed that there is a correlation between vocabulary knowledge and reading comprehension. Our research differs in that we have tried to establish the correlation between vocabulary size and technical text reading comprehension, in other words within the English for Specific Purposes context. The data collected using questionnaire and the results obtained by testing of the students have been processed statistically using R software. Upon presenting the results and the discussion, the conclusion is that further investigation is required and the suggestions are offered accordingly for the future study of relationship between vocabulary size and technical text reading comprehension.
\end{abstract}

Key words: vocabulary size, reading comprehension, pilot study, English for Specific Purposes, Vocabulary Size Test 